Case Report

\title{
A Rare Case of Recurrent Mucoepidermoid Carcinoma of the Nasal Vestibule
}

\author{
Vladimir Bedeković, ${ }^{1}$ Miro Leventić, ${ }^{2}$ Boris Jelavić, ${ }^{2}$ Robert Trotić, \\ Mihael Ries, ${ }^{1}$ Mirjana Kostić, ${ }^{3}$ and Tomislav Lauc $^{4}$ \\ ${ }^{1}$ School of Medicine, Department of Otorhinolaryngology and Head and Neck Surgery, Sisters of Mercy University Hospital Center, \\ University of Zagreb, Zagreb, Croatia \\ ${ }^{2}$ School of Medicine, Department of Otorhinolaryngology and Head and Neck Surgery, \\ University of Mostar, Mostar, Bosnia and Herzegovina \\ ${ }^{3}$ School of Medicine, Croatian Health Insurance Fund, Zagreb, Croatia \\ ${ }^{4}$ School of Dental Medicine, Dental Clinic Apolonia, Zagreb, Croatia
}

Correspondence should be addressed to Mirjana Kostić; mirjana.kostic@hzzo.hr

Received 18 April 2017; Accepted 1 August 2017; Published 13 September 2017

Academic Editor: Constantine Gennatas

Copyright (c) 2017 Vladimir Bedeković et al. This is an open access article distributed under the Creative Commons Attribution License, which permits unrestricted use, distribution, and reproduction in any medium, provided the original work is properly cited.

\begin{abstract}
We report a rare case of a large recurrent mucoepidermoid carcinoma (RMEC) in an 81-year-old female smoker, which has originated in the right nasal vestibule. The recurrent tumour was inadequately treated for 6 years. It was a slow-growing tumour for 3 years and then began to enlarge at a higher pace. In the next three years it has covered a large part of the face. The patient had refused any medical treatment. The tumour caused breathing and swallowing difficulties. Because of the profuse bleeding from the tumour, the patient underwent emergency surgery. Surgical treatment consisted of rhinectomy and resection of the central upper lip and part of the right cheek. The facial defect was reconstructed immediately. Recovery from surgery was fast with no complications. Postoperative Multislice Computed Tomography scan showed no metastases so the patient did not receive any chemotherapy or radiotherapy. During a 2.5 years' follow-up period there was no recurrence of the disease.
\end{abstract}

\section{Introduction}

Mucoepidermoid carcinomas (MEC) of the nasal vestibule (NV) are extremely rare. Only a few cases were reported. MEC is the most common primary carcinoma of major and minor salivary glands of the oral cavity and pharynx, the lacrimal glands, and the parotid. It accounts for less than $1 \%$ of all malignancies of the head and neck.

The pathogenesis is not known. [1-9]. The guidelines for cancers in the nasal area are not uniformly accepted. Recurrent carcinomas of the nasal vestibule have never been studied as a specific entity. The prognosis of MEC depends on many factors including early diagnosis, histological grade, and the clinical stage of the tumour. Treatment options include surgery, radiotherapy, and chemotherapy [10-12]. MEC of the $\mathrm{NV}$ is usually a low-grade and slow-growing cancer with very rare metastases which are often treated only with surgical resection, depending on the extent of the disease. Combined surgery and postoperative radiotherapy has been advocated for intermediate and high-grade tumours [13, 14]. Some studies have found that smoking tobacco, alcohol consumption, and previous radiation exposure might increase the risk of NV cancer [15].

\section{Case Report}

An 81-year-old female smoker with cardiac arrhythmia is presented with a 6-year history of inadequate treatment of recurrent mucoepidermoid carcinoma (RMEC) originating from the right NV. Nine years ago, the patient had experienced breathing difficulties through her right nostril for 3 weeks. Nasal endoscopy revealed a $1 \times 1 \mathrm{~cm}$, painless, fixed, round, smooth-surfaced, protruding mass in the right nasal vestibule. Neck examination showed no enlarged lymph 


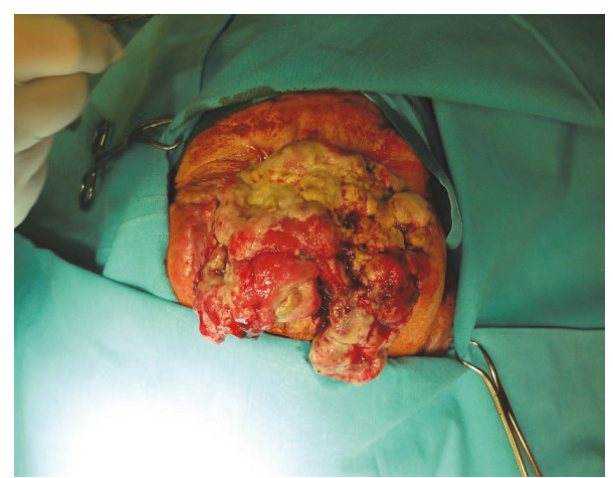

(a) Preoperative view of a patient with large recurrent tumour of the nasal vestibule

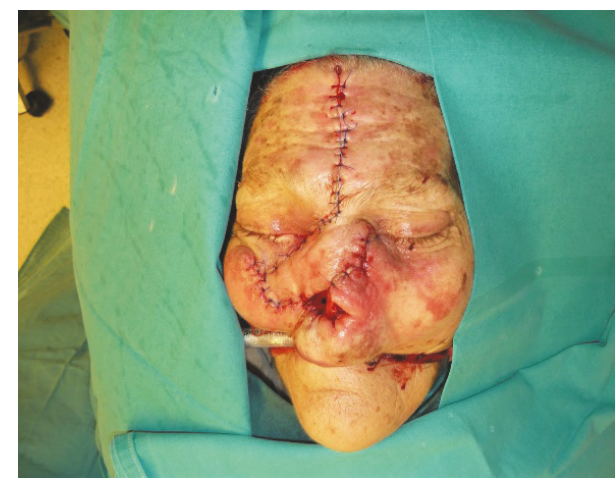

(c) Completed reconstruction of the facial defect

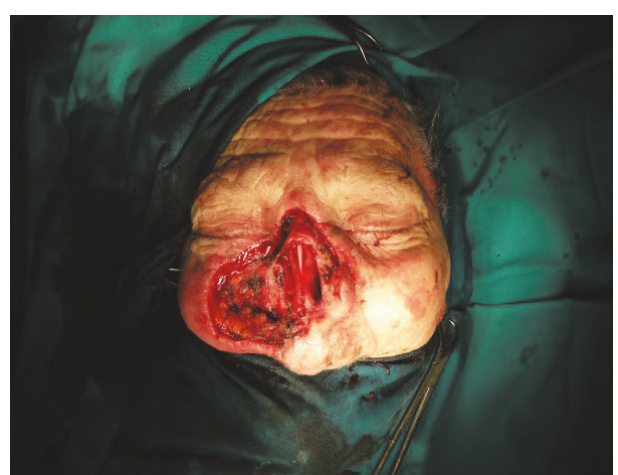

(b) Intraoperative surgical defect involving the nose, the central portion of the upper lip, and part of right cheek

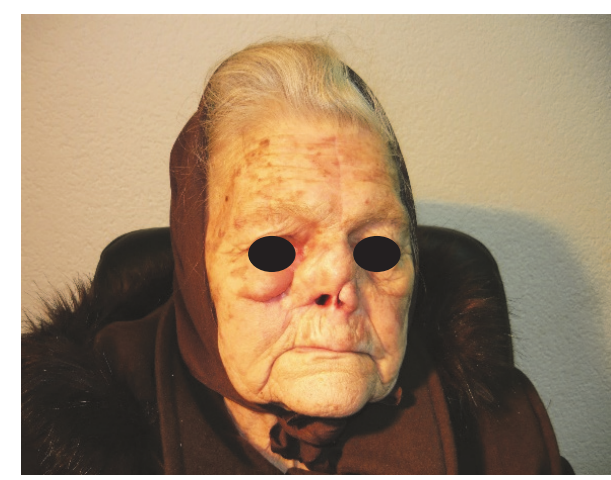

(d) Good aesthetic result nine months after surgery

Figure 1

nodes. The tumour mass was fully excised and histologically identified as low-grade mucoepidermoid carcinoma. The patient did not receive any therapy. The tumour has recurred within 6 months. A biopsy confirmed the previous diagnosis. Multislice Computed Tomography (MSCT) scan showed no regional or distant metastatic spread, and the patient has refused surgical or any other medical treatment. RMEC was a slow-growing tumour for 3 years and then began to enlarge at higher pace. In the next three years, it has affected almost the whole face: the nasal septum, columella, philtrum, and a large part of both cheeks. The tumour bled occasionally. The patient's condition has deteriorated in time. In spite of her very serious condition, the patient once again refused medical treatment. On the day of admission to the hospital the tumour bled profusely, and the patient underwent emergency surgery. There was no time for radiological examination (Figure 1(a)). The patient received the blood transfusion before, during, and after surgery. Surgical treatment consisted of rhinectomy and resection of the central upper lip and part of the right cheek (Figure 1(b)). The large facial defect was reconstructed immediately with the vertical paramedian forehead flap, cheek flap, and nasolabial flap (Figure 1(c)). Histology finding confirmed a low-grade MEC. Seven days after surgery the patient's general condition was good; respiration, speech, and eating were normal. Senses of taste and smell were wellpreserved.

\section{Discussion}

We found no articles addressing the recurrent mucoepidermoid carcinoma of the nasal vestibule in available literature. As of our knowledge, this is the first described case. In our patient a large RMEC caused breathing, speaking, chewing, swallowing, eating, and sleeping difficulties. Impaired sense of smell, facial pain, and headache were not present. The bad body odor and fetid nasal discharge were emitted as a result of accompanying paranasal sinusitis, and as a result of malacia of decomposed tumour masses. RMEC was histopathologically diagnosed as a low-grade malignant tumour following biopsy, which was confirmed after tumour excision. Postoperative MSCT scan showed no regional or distant lymph node metastases, so there was no need for chemotherapy or radiotherapy. Cardiac arrhythmia and secondary anemia were well-controlled by adequate therapy. Nine months after the operation the aesthetic aspect was more than satisfactory (Figure 1(d)). No recurrence of the disease was noted during a follow-up period of 2.5 years.

\section{Conclusion}

In case of a large, profusely bleeding tumour surgery is a procedure of choice.

For treatment of recurrent mucoepidermoid carcinoma delayed surgery may be successful. 
Mucoepidermoid carcinoma of the nasal vestibule is extremely rare, and it has never been studied as a specific entity. Treatment of mucoepidermoid carcinomas has no uniformly accepted guidelines, and each case has to be treated individually.

\section{Disclosure}

Surgery was carried out at the University of Mostar, School of Medicine, Department of Otorhinolaryngology and Head and Neck Surgery, Mostar, Bosnia and Herzegovina.

\section{Conflicts of Interest}

The authors declare no conflicts of interest.

\section{References}

[1] H. Haraguchi, S. Ebihara, M. Saikawa et al., "Malignant tumors of the nasal cavity. Review 60-case series," Japanese Journal of Clinical Oncology, vol. 25, pp. 188-194, 1995.

[2] V. Subramaniam, P. Kumar, and M. Thahir, "Mucoepidermoid carcinoma of the nasal cavity-a rare tumour," Klinická Onkologie: Casopis Ceské a Slovenské Onkologické Spolecnosti, vol. 23, pp. 354-357, 2010.

[3] G. R. Thomas, J. J. Regalado, and M. McClinton, "A rare case of mucoepidermoid carcinoma of the nasal cavity," Ear, Nose and Throat Journal, vol. 81, no. 8, pp. 519-522, 2002.

[4] C. Salazar, J. Marcos, M. R. De Saa, J. L. Sánchez-Jara, M. García, and M. A. González, "Mucoepidermoid carcinoma of the nasal vestibulum," Acta Otorrinolaringológica Española, vol. 51, pp. 729-732, 2000

[5] A. N. Barcellos, C. P. Carvalho, D. C. Teixeira, J. A. P. Machado, A. C. Barreiros, and T. N. Barcellos, "Rare case of mucoepidermoid carcinoma of the nasal septum," Internat Archives of Otorhynolaryngology, vol. 12, pp. 560-577, 2008.

[6] J. D. Rosdeutscher and R. Burnette, "Nasal mucoepidermoid carcinoma," Otolaryngology - Head and Neck Surgery, vol. 129, no. 3, pp. 291-292, 2003.

[7] X.-M. Zhang, J.-Z. Cao, J.-W. Luo et al., "Nasopharyngeal mucoepidermoid carcinoma: a review of 13 cases," Oral Oncology, vol. 46 , no. 8 , pp. $618-621,2010$.

[8] L. D. R. Thompson, "Mucoepidermoid carcinoma," Ear, Nose, \& Throat Journal, vol. 84, no. 12, pp. 762-763, 2005.

[9] G. Landman and E. R. Farmer, "Primary cutaneous mucoepidermoid carcinoma: report of a case," Journal of Cutaneous Pathology, vol. 18, no. 1, pp. 56-59, 1991.

[10] J. A. Bishop, "Recently described neoplasms of the sinonasal tract," Seminars in Diagnostic Pathology, vol. 33, no. 2, pp. 62-70, 2016.

[11] J. P. Jeannon, P. J. Riddle, J. Irish et al., "Prognostic indicators in carcinoma of the nasal vestibulae," Clinical Otolaryngology, vol. 32, no. 19, 2007.

[12] C. C. Wang, "Treatment of carcinoma of the nasal vestibule by irradiation," Cancer, vol. 38, no. 1, pp. 100-106, 1976.

[13] Y. Nakamura, Y. Nakamura, A. Saito, Y. Fujisawa, Y. Kawachi, and F. Otsuka, "High-grade mucoepidermoid carcinoma of the columella successfully reconstructed using bilateral nasolabial flaps set up in a sandwich shape and an auricular cartilage graft after surgical resection," Journal of Dermatology, vol. 40, no. 11, pp. 911-914, 2013.
[14] G. C. Burget and R. L. Walton, "Optimal use of microvascular free flaps, cartilage grafts, and a paramedian forehead flap for aesthetic reconstruction of the nose and adjacent facial units," Plastic and Reconstructive Surgery, vol. 120, no. 5, pp. 1171-1207, 2007.

[15] A. 'T Mannetje, M. Kogevinas, D. Luce et al., "Sinonasal cancer, occupation, and tobacco smoking in European women and men," American Journal of Industrial Medicine, vol. 36, no. 1, pp. 101-107, 1999. 


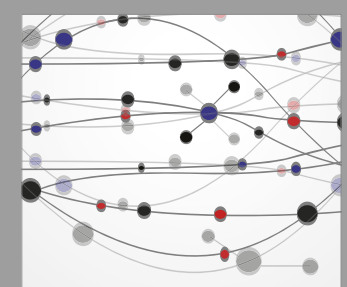

The Scientific World Journal
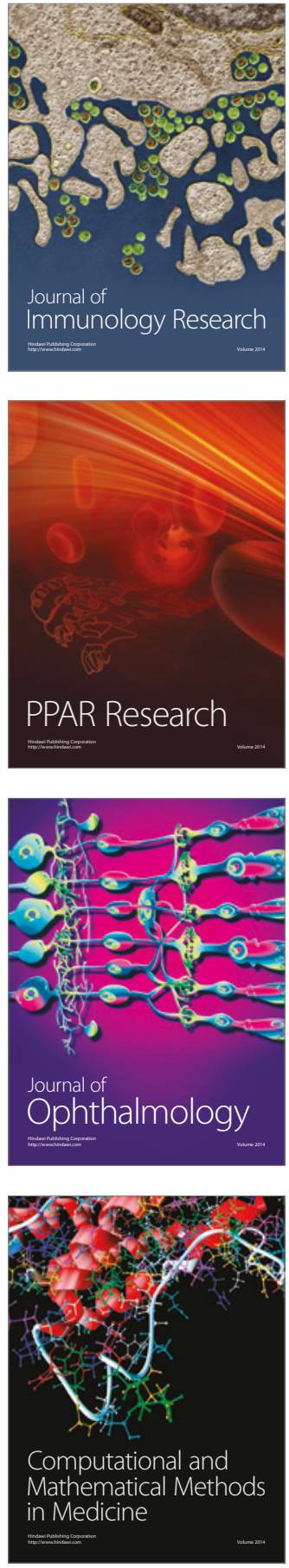

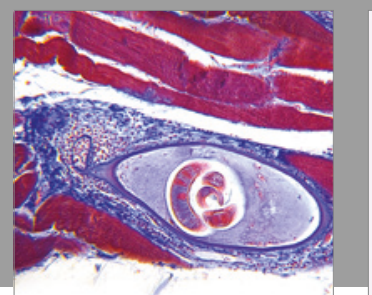

Gastroenterology Research and Practice
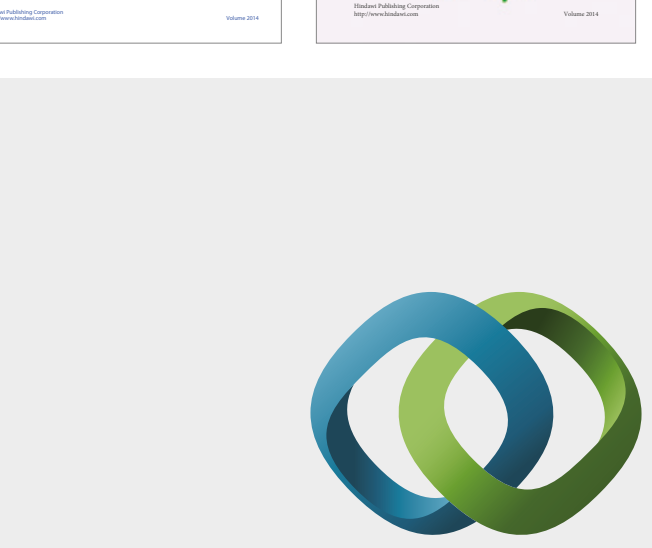

\section{Hindawi}

Submit your manuscripts at

https://www.hindawi.com
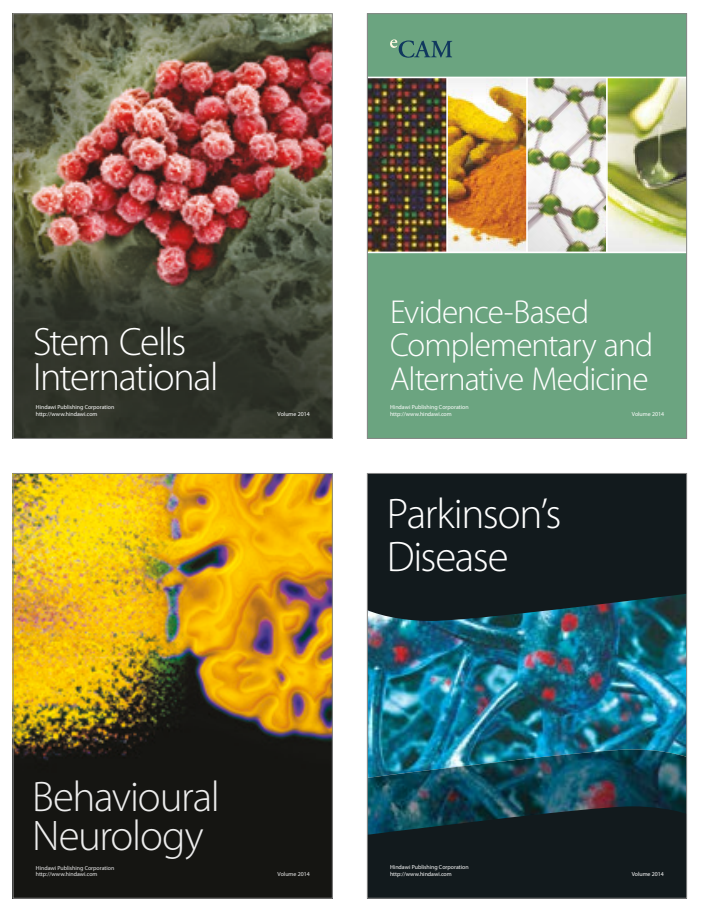
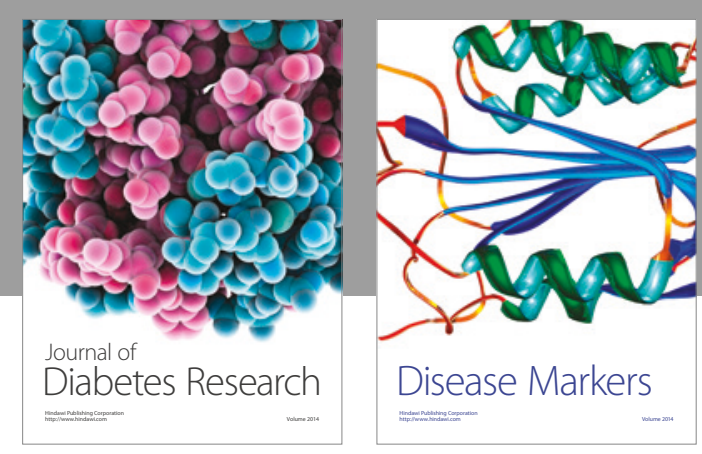

Disease Markers
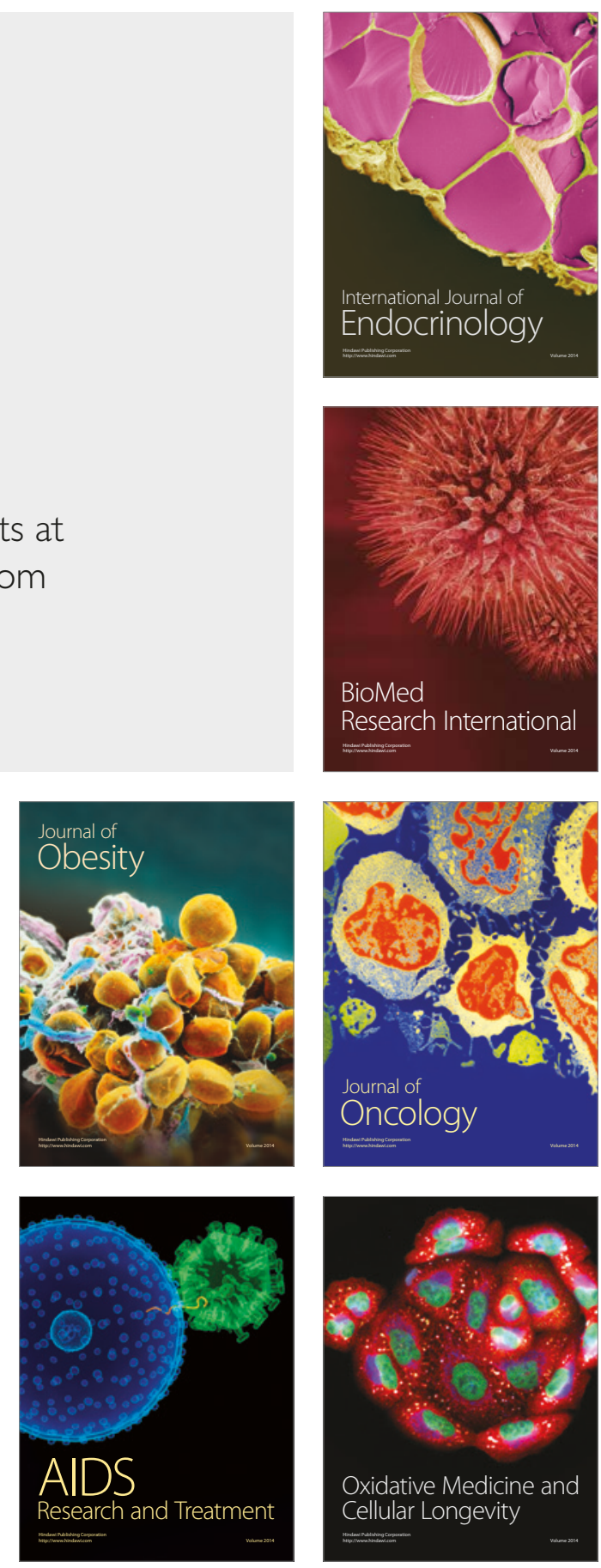